\title{
Influence of Two Desensitizer Agents on the Microleakage of Adhesively Luted Ceramic Inlays
}

\author{
Esra Uzer Celik ${ }^{a}$ \\ Nazli Kumbaracib \\ Ebru Calc \\ Murat Turkun ${ }^{\mathrm{d}}$
}

\section{ABSTRACT}

Objectives: The purpose of this study was to evaluate the effects of two different desensitizers (Hemaseal \& Cide and Aqua Prep F) on the microleakage of ceramic inlay restorations luted with adhesive resin cement.

Methods: Cylindrical Class V cavities were prepared on the buccal surfaces of thirty extracted human third molars. One of the desensitizers (either Hemaseal\&Cide, Advantage Dental Products Inc. or Aqua-Prep F, Biscol was applied to the cavities. Ten samples were used as controls. Ceramic inlays were fabricated using the heat-pressed glass ceramic technique (IPS Empress II). Inlay restorations were luted using adhesive cement (Variolink II, Ivoclar-Vivadent). The restorations were properly finished, stored in distilled water at $37^{\circ} \mathrm{C}$ for $24 \mathrm{~h}$ and subjected to 1000 thermal cycles. The microleakage scores were examined using a stereomicroscope at the 30x magnification after each sample was stained with $0.5 \%$ basic fuchsin. The data were analyzed using Kruskall Wallis and Mann Whitney U tests ( $P=0.05)$.

Results: Aqua-Prep F samples showed significantly higher microleakage scores at the enamel margins than did the Hemaseal \& Cide and control groups $(P<.05)$. Hemaseal \& Cide application led to less microleakage than the other groups both at the enamel and dentin margins $(P<.05)$.

Conclusions: Hemaseal \& Cide desensitizer decreased the microleakage process at the enamel and dentin margins of inlay restorations luted with adhesive luting cement, while Aqua-Prep F increased the leakage scores at the enamel margins. (Eur J Dent 2011;5:77-83)

Key words: Desensitizers; Microleakage; SEM; Inlay restorations.

Assistant Professor, Department of Restorative Dentistry, Faculty of Dentistry, Suleyman Demirel University, Isparta, Turkey.

b Undergraduate Senior Student, Faculty of Dentistry, Ege University, Izmir, Turkey.

Associate Professor, Department of Prosthodontics, Faculty of Dentistry, Ege University, Izmir, Turkey.

d Professor, Department of Restorative Dentistry and Endodontics, Faculty of Dentistry, Ege University, Izmir, Turkey.

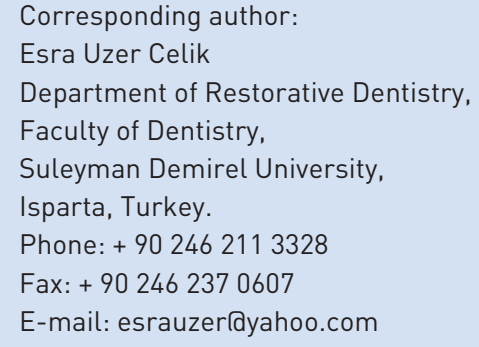




\section{INTRODUCTION}

Adhesive resin luting cements are used extensively in dentistry to cement ceramic, cast metallic, and indirect composite restorations. A strong and durable bond is required in order to avoid the detachment of restorations and to prevent microleakage, postoperative sensitivity, secondary dental caries, and tooth fractures when such cements are used.

Despite recent developments in dental restorative materials and techniques, postoperative sensitivity is one of the well-known problems following restorative procedures. ${ }^{1}$ There are several explanations for postoperative sensitivity. In clinical practice, enamel is generally removed with rotary instruments leading to the exposure of dentinal tubules. When the dentinal tubules are opened, the adverse effects of cavity preparation, such as excessive heat and dentin dehydration reach the pulp more easily. ${ }^{2}$

The clinical cavity depth has a significant influence on the appearance of postoperative sensitivity. In a previous study, caries profunda showed a four times higher risk of failure due to postoperative sensitivity compared to superficial or moderate caries. ${ }^{3}$ Microleakage is one of the main factor affecting the incidence of postoperative dentistry. ${ }^{4}$ If there is a discontinuity in the coating of the cavity wall by the bonding system or a micro-porous zone beneath the hybrid layer, hydrodynamic fluid shift or bacterial toxin penetration into dentin tubules may occur. ${ }^{5}$ An approximate $1.6 \mu \mathrm{m} /$ day of bacterial invasion through the gap between restoration and the cavity wall has been found to occur over time. ${ }^{6}$ Bacteria can infiltrate the tubules in a relatively short period of time (up to 4 days). The odontoblastic process, collagen fibers, kinetics of tubular fluid, and immunological function do not seem to be sufficient to inhibit this process. ${ }^{7}$

The failure of restorations due to secondary caries have been reported in several clinical trials of direct and indirect restorations..$^{8-10} \mathrm{~A}$ prospective clinical study evaluating 64 indirect inlays/onlays over a period of 48 to 75 months with a mean time of 59 months reported one failure $(2 \%)$ due to caries. ${ }^{8} \mathrm{~A}$ clinical study evaluating the durability of a recently developed low-shrinkage resin composite indicated that secondary caries was the main reason for failure $(8 \%)$ at a five-year evaluation. ${ }^{9}$ A randomized clinical trial examining the clinical performance of composite resin materials used for fillings $(n=56)$ and indirect inlays ( $n=84$ ) reported two failures ( $4 \%$ ) for fillings and four failures $(5 \%)$ for inlays due to secondary caries at an 11 -year follow-up. ${ }^{10}$

To reduce postoperative sensitivity, dentists increasingly use desensitizers based on hydroxyethyl metacrylate (HEMA), fluoride, and chlorhexidine gluconate after tooth preparation for restorations. Some ingredients of these desensitizers may induce chemical interactions with organic substances of the dentin that may consequently affect the sealing and bonding characteristics of the adhesive resin cement. ${ }^{11-13}$ The function of fluoride present in dentin desensitizers is to seal the dentinal tubules with incorporation of mainly HEMA, which increases the infiltration ability of primers. ${ }^{6}$

Chlorhexidine is an antiseptic with a wide spectrum of action that has been used over the past two decades for the chemical control of bacterial plaque and the prevention of dental caries. ${ }^{14}$ It is the most effective antimicrobial agent that can be used against $S$. mutans, ${ }^{15}$ and it has a proven ability to delay bond degradation. ${ }^{16}$ For this reason, chlorhexidine has been added to the desensitizers in recent years. Although there is no information concerning the effects of chlorhexidinebased desensitizers on the bonding performance of composites to tooth tissues, previous studies have shown that application of chx-containing cavity disinfectants before or after acid-etching procedures does not have a negative effect on the shear bond strength; in fact, this procedure may increase bond strength and durability. ${ }^{11-13}$

On the other hand, contradictory results have also been reported in the literature regarding the bonding effectiveness of desensitizers affecting by the blocking the dentin tubules with the crystals deposition. Some studies have demonstrated that the bond strength of composite to enamel and dentin was not reduced when these desensitizers were used. ${ }^{17-19}$ However, some studies reported a reduction in bond strength caused by poor resin infiltration and micromechanical retention due to crystal precipitation of desensitizers on the enamel and dentin surface. ${ }^{20-22}$ Nevertheless, a limited number of studies is available concerning the effect of desensitizers containing fluoride and chlorhexidine gluconate on the microleakage of adhesively luted ceramic inlays. 
The aim of this study was to evaluate the effect of two different desensitizers (Hemaseal \& Cide and Aqua Prep F) on the microleakage of adhesively luted ceramic inlays. The null hypothesis tested was that Hemaseal \& Cide, including HEMA and chlorhexidine gluconate and Aqua Prep F, including both HEMA and sodium fluoride do not increase the microleakage when used prior to the bonding procedures of adhesively luted ceramic inlays.

\section{MATERIALS AND METHODS}

Thirty extracted caries-free human third molars were used in this study. Immediately after extraction, the teeth were scraped of any residual tissue tags, pumiced, and washed under running tap water. The teeth were stored in distilled water at $+4^{\circ} \mathrm{C}$ until required. Standardized, non-beveled cylindrical Class $\vee$ cavities were prepared on the buccal aspects of each tooth with round internal angles, $1 \mathrm{~mm}$ below the CEJ using cylindrical 13.8 $\mathrm{mm}$ in diameter and $1.8 \mathrm{~mm}$ in length) (041-038C, MDT Micro Diamond Technologies Ltd, Afula, Israel) and $6^{\circ}$ conical diamond burs (702.8KR, Abrasive Technology, London, United Kingdom). Standardization of the cavity size was accomplished by using the cylindrical diamond burs in similar dimensions with the prepared cavities and employing the handpiece in a paralelometer during preparation. After preparation, the teeth were randomly divided into three groups.

Impressions were made with polyvinyl siloxane material (Imprint II VPS, 3M ESPE AG, Seefeld, Germanyl and poured in a vacuum mixed polyurethane die material (Alpha Die MF, Schültz-Dental $\mathrm{GmbH}$, Rosbach, Germanyl according to the manufacturer's instructions. IPS Empress II ceramic inlays were fabricated according to the manufacturer's instructions and then glazed.

Ceramic inlays were etched with hydrofluoric acid for $20 \mathrm{~s}$, and then a layer of silane coupling was applied to the ceramic bonding surface for 60 $s$ and air-dried.

The enamel and dentin margins of inlay cavities were etched with the phosphoric acid gel (Unietch, Bisco, IL, USA) for $15 \mathrm{~s}$ and rinsed thoroughly with water for approximately $5 \mathrm{~s}$ and air-dried for 2-4 s to remove excess moisture leaving the dentin surface with a slightly glossy, wet appearance.

The desensitizers tested in this study were
Aqua-Prep F (Bisco) and Hemaseal \& Cide (Advantage Dental Products, Inc., Lake Orion, USA) (Table 1).

In Group 1, Aqua-Prep F was used before the application of primer. Two drops of Aqua-Prep $F$ were dispensed into a mixing well. It was applied with a brush to the cavity surfaces. Aqua-Prep F was allowed to soak for $20 \mathrm{~s}$ and gently air dried to remove excess moisture to avoid pooling, especially at the internal line angles of the preparation. The resulting surface was wet and had a shiny appearance.

In Group 2, Hemaseal \& Cide was applied with a brush as a desensitizer. The excess was removed by gently air drying to avoid pooling, especially at the internal line angles of the preparation. The resulting surface was wet and had a shiny appearance.

In Group 3, no desensitizer application was performed.

One drop of the primer (Syntac, Ivoclar Vivadent, Schaan, Liechtenstein) was applied to the cavity surfaces for $15 \mathrm{~s}$ and gently air-dried. A layer of bonding resin (Syntac) was applied with a brush for $10 \mathrm{~s}$ and spread gently with air. After application of enamel bonding agent (Heliobond, Ivoclar Vivadent) to the cavity and the bonding surface of the ceramic inlay restorations, the cavities were filled with Variolink II (Ivoclar Vivadent) and inlays were placed into the cavities using light pressure, and cured briefly (1-2 s) with light. Then the excess material was removed using a scaler. The restoration margins were covered with glycerin gel. The luting cement was light cured for 40 $s$ from the buccal surface. The light activating unit was Optilux 501 (Kerr Orange, CA, USA), which was tested prior to each sample. The output of this unit did not drop $500 \mathrm{~W} / \mathrm{cm}^{2}$. After final polymerization, the glycerin gel was rinsed off.

Excess material was removed with finishing diamond burs and flexible discs. The restoration margins were finished with silicone polishers (Astropol -F, -P, Ivoclar Vivadent).

After cementation, specimens were stored in distilled water at $37^{\circ} \mathrm{C}$ for $24 \mathrm{~h}$ and then subjected to 1000 thermal cycles between the baths of 5 and $55^{\circ} \mathrm{C}$, with a dwell time of $30 \mathrm{~s}$. The teeth were subsequently coated with nail varnish $1 \mathrm{~mm}$ short of the restoration margins to seal open dentin tubules. The dye penetration test was conducted 
in a $0.5 \%$ basic fuchsin dye solution for $24 \mathrm{~h}$. The teeth were then rinsed, and Class $\mathrm{V}$ restorations were sectioned into three parts longitudinally in a bucco-lingually plan with a slow-speed diamond blade (Struers, Ballerup, Danmark). The sections from the centers of the restorations were 2-mmthick, while the other sections were 1-mm-thick. In this way, four surfaces leither mesial or distal surfaces of 1-mm-thick samples and both mesial and distal surfaces of 2-mm-thick samples) were obtained from one restoration for microleakage evaluation. One hundred twenty surfaces $(n=40)$ were evaluated at $30 x$ magnification under a stereomicroscope (Olympus Co., Tokyo, Japan) by two examiners who were calibrated prior to the study.

The extent of the microleakage was scored according to the following criteria:

$0=$ no leakage visible,

$1=$ penetration of dye along the cavity wall, but less than $1 / 2$ the length,

$2=$ penetration of dye along the wall, but short of the axial wall,

$3=$ penetration of dye to and along the axial wall.

Leakage scores at occlusal and gingival margins for each group were compared with the nonparametric statistical tests, Kruskall Wallis and Mann-Whitney U. Significance was considered at the 0.05 level.

\section{RESULTS}

The test of intra-examiner and inter-examiner agreement resulted in a Cohen's kappa statistic of 0.85 and 0.88 . The microleakage scores are shown in Table 2. Aqua-Prep F applied samples showed significantly higher microleakage scores at the occlusal margins than did the Hemaseal \& Cide and control groups $(\mathrm{P}<.05)$. Hemaseal \& Cide application led to less microleakage than the other groups, both at the enamel and dentin margins $(P<.05)$. No significant difference was shown between the other groups for either enamel or dentin margins.

\section{DISCUSSION}

Most of the desensitizers are indicated by their manufacturers for use under restorative materials prior to applying primers and bonding agents in order to prevent postoperative sensitivity. Although they are good alternatives for reducing sensitivity, it is also important to evaluate the possible adverse effects of these desensitizing agents on the adhesion performance of restorative materials and the marginal quality of restorations.

In the present study, the effect of desensitizers on the microleakage of adhesively luted ceramic inlays was evaluated in Class V cavities. The reason for studying Class $V$ cavities was that (1) Class $\mathrm{V}$ cavities have unfavorable $\mathrm{C}$-factors, resulting in high contraction scores within an adhesively fixed resin material, (2) Class $V$ restoration margins are located in enamel as well as in dentin, (3) preparation and restoration of Class $\mathrm{V}$ lesions are minimal and relatively easy, thereby somewhat reducing practitioner variability, and (4) it is easier to standardize the preparation of Class $\mathrm{V}$ cavities than Class II cavities. ${ }^{23,24}$

Different techniques have been described for studies of margin quality. The most widely accepted method is the dye penetration test. ${ }^{25}$ In our study, $0.5 \%$ basic fuchsin solution was used for the dye penetration test. All restorations were

Table 1. Desensitizers used in this study.

\begin{tabular}{|c|c|c|}
\hline Desensitizers & Active components & Manufacturer \\
\hline Hemaseal \& Cide & HEMA, $4 \%$ chlorhexidine gluconate, water & Advantage Dental Products, Inc, Lake Orion, USA \\
\hline Aqua-Prep F & HEMA, $2 \% \mathrm{NaF}$ & Bisco, IL, USA \\
\hline
\end{tabular}

Table 2. Results of microleakage test

\begin{tabular}{lccccccc}
\hline & \multicolumn{2}{c}{ Occlusal margin } & & \multicolumn{2}{c}{ Gingival margin } \\
\hline & 0 & 1 & 2 & 3 & 0 & 1 & 2 \\
Hemaseal \& Cide & 26 & 12 & 2 & - & 31 & 4 & 1 \\
Aqua-Prep F & 7 & 15 & 5 & 13 & 21 & 11 & 5 \\
Control & 14 & 11 & 7 & 8 & 19 & 9 & 8 \\
\hline
\end{tabular}


previously subjected to thermal cycling in order to subject the restorations to thermal expansion and contraction challenges. The different thermal expansion coefficients of tooth tissue from the restorative materials may lead to gap formation. ${ }^{26} \mathrm{As}$ such, to assess the in vitro performance of resin materials, thermal cycling is the common method used to simulate the long-term stresses to which the resin restorations are exposed. ${ }^{27}$

The microleakage scores of HEMA-based desensitizers at the dentin margins were less than those of the control group, although the differences were significant only between Hemaseal \& Cide and the control group. The higher leakage scores for the control group might be related to the use of the acetone-based adhesive system. Previous studies have demonstrated that the moisture degree of dentin was effective on the bond strength of adhesive systems. ${ }^{28-29}$ The water-based systems require a drier dentin surface, while acetonebased systems require a rather wetter dentin surface for improved bond strength. ${ }^{28}$ Although the amount of dentin surface moisture was not assessed in this study, HEMA in the desensitizers might have contributed to improve the marginal quality of the experimental groups. HEMAcontaining hydrophilic monomers rehydrate the collapsed collagen matrix caused by air-drying and facilitate subsequent resin infiltration into the interfibrillar spaces of demineralized dentin. ${ }^{30,31}$ The addition of HEMA to water lowers the vapor pressure of water and prevents water from evaporating prematurely during rehydration of the collapsed dentin matrix. ${ }^{32}$ In previous studies, HEMA significantly improved bond strength by enhancing the wetting of dentin. ${ }^{30,31}$

The better results for the Hemaseal \& Cide group at the dentin margin as compared to the Aqua Prep F group may be attributed to the ingredients of those desensitizers other than HEMA, such as sodium fluoride and chlorhexidine gluconate. It has been shown that fluoride ions penetrating into the dentin enhance the mineralization of dentin; it can be anticipated that the presence of fluoride in the desensitizer may yield to obturation of dentinal tubules and impair the adhesion of resin-based cements to tooth tissues. Inconsistent results have been reported regarding the effect of fluoride ions on the adhesion performance of composites to dentin. Some authors have dem- onstrated that fluoride treatment on sound dentin decreased the bond strength to dentin, ${ }^{22}$ while others have reported that fluoride application to demineralized did not interfere with the process of resin bonding. ${ }^{19,33}$ In addition, it has been reported that pre-treatment of enamel and dentin with fluoride prior to the placement of a resin bonding agent produced no significant change in microleakage. ${ }^{34}$

Contrary to the inconsistent results in terms of the effect of fluoride ions on the adhesion performance of composite to dentin, chlorhexidine gluconate application prior to acid-etching did not reveal any adverse effects on immediate composite-adhesive bonds in dentin ${ }^{11,12,35}$ and enamel. ${ }^{35}$ Furthermore, chlorhexidine gluconate-based disinfectant did not adversely affect the shear bond strength of adhesively luted ceramics (Empress II) to dentin. ${ }^{13}$ In addition, chlorhexidine has shown to have beneficial effects on the preservation of dentin bond strength as an MMP inhibitor, when applied prior to bonding with no further rinsing. When applied in this manner, the naked collagen fibrils were exposed to chlorhexidine that was then sealed into the fibrils by adhesive resins. ${ }^{36}$

According to leakage scores, Aqua Prep F demonstrated the worst results at the enamel margins. This may have resulted from the presence of sodium fluoride, which may precipitate and cover the demineralized surface, thus minimizing micromechanical retention. These results were in accordance with the results of a number of previous studies. Barcroft et $\mathrm{al}^{20}$ reported a slight reduction in bond strength with the use of $2.0 \%$ aqueous sodium fluoride in the enamel samples. Meng et $\mathrm{al}^{21}$ showed that the application of acidulated phosphate fluoride after the acid etching of enamel has an adverse effect on the orthodontic bond strength of human enamel. On the other hand, some authors have reported that the exposure of enamel to sodium fluoride, stannous fluoride, or acidulated phosphate fluoride has no adverse effect on in vitro bond strength and microleakage between the enamel and composites. ${ }^{17,18,33,34}$

The application sequence of the disinfectant is also an important factor to be considered. Some clinicians prefer to apply disinfectants after tooth preparation, ${ }^{19}$ while the others prefer to apply them after etching..$^{37,38}$ In previous studies, 
the oxalate-based desensitizers with desensitizing mechanism that are similar to fluoride-based ones reduced the bond strength of adhesive systems when they were applied before the dentin was acid-etched. ${ }^{39,40}$ This result may be explained by the presence of acid-resistant calcium oxalate crystals on the dentin surface that may prevent etching and the penetration of adhesive resins into the dentin surface. In this situation, additional enamel etching to remove these crystals and increase the microretentive topography was recommended..$^{40}$ In the present study, the desensitizers were applied after acid-etching procedures and additional etching was not performed. This was done because the manufacturers recommend the use of both desensitizers after etching and do not propose additional etching after the application of desensitizers.

\section{CONCLUSIONS}

Within the limitations of this study, while the use of Hemaseal \& Cide decreased the microleakage process at the enamel and dentin margins of IPS Empress II inlay restorations luted with an adhesive luting cement, Aqua-Prep F increased the leakage scores at the enamel margins. The increased microleakage at enamel margins may result from the presence of sodium fluoride in this desensitizer, which may precipitate and cover the surface, reducing the micromechanical retention between resin monomers and enamel.

\section{REFERENCES}

1. Opdam NJ, Loomans BA, Roeters FJ, Bronkhorst EM. Fiveyear clinical performance of posterior resin composite restorations placed by dental students. J Dent 2004;32:379383.

2. Swift EJ Jr, Lloyd AH, Felton DA. The effect of resin desensitizing agents on crown retention. J Am Dent Assoc 1997;128:195-200.

3. Auschill TM, Koch CA, Wolkewitz M, Hellwig E, Arweiler NB. Occurrence and causing stimuli of postoperative sensitivity in composite restorations. Oper Dent 2009;34:3-10.

4. Felton D, Bergenholtz G, Cox CF. Inhibition of bacterial growth under composite restorations following GLUMA pretreatment. J Dent Res 1989;68:491-495.

5. Akpata ES, Sadiq W. Post-operative sensitivity in glass-ionomer versus adhesive resin-lined posterior composites. Am J Dent 2001;14:34-38.
6. Arrais CAG, Chan DCN, Giannini M. Effects of desensitizing agents on dentinal tubule occlusion. J Appl Oral Sci 2004;12:144-148.

7. Dagostin A, Ferrari M. Effect of resins sealing of dentin on the bond strength of ceramic restorations. Dent Mater 2002; 18:304-310

8. Leirskar J, Nordbo H, Thoresen NR, Henaug T, von der Fehr FR. A four to six years follow-up of indirect resin composite inlays/onlays. Acta Odontol Scand 2003;61:247-251.

9. van Dijken JW, Lindberg A. Clinical effectiveness of a lowshrinkage resin composite: a five-year evaluation. $J$ Adhes Dent 2009;11:143-148.

10. Pallesen U, Qvist V. Composite resin fillings and inlays. An 11-year evaluation. Clin Oral Invest 2003;7:71-79.

11. Say EC, Koray F, Tarim B, Soyman M, Gülmez T. In vitro effect of cavity disinfectants on the bond strength of dentin bonding systems. Quintessence Int 2004;35:56-60.

12. Turkun M, Turkun LS, Kalender A. Effect of cavity disinfectants on the sealing ability of nonrinsing dentin-bonding resins. Quintessence Int 2004;35:469-476.

13. Turkun M, Cal E, Toman M, Toksavul S. Effects of dentin disinfectants on the shear bond strength of all-ceramics to dentin. Oper Dent 2005;30:453-460.

14. Fardal 0, Turnbull RS. A review of the literature on use of chlorhexdine in dentistry. J Am Dent Assoc 1986;112:863869.

15. Scheie AA. The role of antimicrobials. In: Fejerskov 0 , Kidd EAM, eds. Dental caries: The disease and its clinical management. Oxford: Blackwell Munksgaard; 2003:179188.

16. Carrilho MR, Geraldeli S, Tay F, de Goes MF, Carvalho RM, Tjaderhane L, Reis AF, Hebling J, Mazzoni A, Breschi L, Pashley D. In vivo preservation of the hybrid layer by chlorhexidine. J Dent Res 2007;86:529-533.

17. Damon PL, Bishara SE, Olsen ME, Jakobsen JR. Effects of fluoride application on shear bond strength of orthodontic brackets. Angle Orthod 1996;66:61-64.

18. Koh SH, Chan JT, You C. Effects of topical fluoride treatment on tensile bond strength of pit and fissure sealants. Gen Dent 1998;46:278-280.

19. Nystrom GP, Holtan JR, Douglas WH. Effects of fluoride pretreatment on bond strength of a resin bonding agent. Quintessence Int 1990;21:495-499.

20. Barcroft BD, Childers KR, Harris EF. Effects of acidulated and neutral NaF solutions on bond strengths. Pediatr Dent 1990;12:180-182.

21. Meng CL, Li CH, Wang WN. Bond strength with APF applied after acid etching. Am J Orthod Dentofacial Orthop 1998;114:510-513. 
22. Soeno K, Taira Y, Matsumura H, Atsuta M. Effect of desensitizers on bond strength of adhesive luting agents to dentin. J Oral Rehabil 2001;28:1122-1128.

23. Hahn P, Attin T, Gröfke M, Hellwig E. Influence of resin cement viscosity on microleakage of ceramic inlays. Dent Mater 2001;17:191-196.

24. De Munck J, Van Landuyt K, Peumans M, Poitevin A, Lambrechts $P$, Braem M, Van Meerbeek B. A critical review of the durability of adhesion to tooth tissue: methods and results. J Dent Res 2005;84:118-132.

25. Taylor MJ, Lynch E. Microleakage. J Dent 1992;20:3-10.

26. Versluis A, Douglas WH, Sakaguchi RL. Thermal expansion coefficient of dental composites measured with strain gauges. Dent Mater 1996;12:290-294.

27. Amaral FL, Colucci V, Palma-Dibb RG, Corona SA. Assessment of in vitro methods used to promote adhesive interface degradation: a critical review. J Esthet Restor Dent 2007; 19:340-353.

28. Reis A, Loguercio AD, Azeyedo CL, de Carvalho RM, da Julio Singer M, Grande RH. Moisture spectrum of demineralised dentin for adhesive systems with different solvent bases. J Adhes Dent 2003;5:183-192.

29. Dal-Bianco K, Pellizzaro A, Patzlaft R, de Oliveira Bauer JR, Loguercio AD, Reis A. Effects of moisture degree and rubbing action on the immediate resin-dentin bond strength. Dent Mater 2006;22:1150-1156.

30. Nakaoki Y, Nikaido T, Pereira PN, Inokoshi S, Tagami J. Dimensional changes of demineralized dentin treated with HEMA primers. Dent Mater 2000;16:441-446.

31. Perdigao J, Van Meerbeek B, Lopes MM, Ambrose WW. The effect of a re-wetting agent on dentin bonding. Dental Mater 1999;15:282-295.

32. Pashley EL, Zhang Y, Lockwood PE, Rueggeberg FA, Pashley $\mathrm{DH}$. Effects of HEMA on water evaporation from waterHEMA mixtures. Dent Mater 1998;14:6-10.

33. Dundar M, Cal E, Bulent G, Turkun M, Ozcan M. Influence of fluoride- or triclosan-based desensitizing agents on adhesion of resin cements to dentin. Clin Oral Invest 2010;14:579-586. Epub 2009 Aug 19

34. Nystrom GP, Holtan JR, Olin PS, Douglas WH. Technical note: fluoride pre-treatment effects on microleakage of a resin bonding agent. Dent Mater 1989;5:359-360.

35. El-Housseiny AA, Jamjoum $H$. The effect of caries detector dyes and a cavity cleansing agent on composite resin bonding to enamel and dentin. J Clin Pediatr Dent 2000;25:57-63.

36. Carrilho MR, Tay FR, Pashley DH, Tjäderhane L, Carvalho RM. Mechanical stability of resin-dentin bond components. Dent Mater 2005;21:232-241.
37. Itthagarun A, King NM, Wefel JS, Tay FR, Pashley DH. The effect of fluoridated and non-fluoridated rewetting agents on in vitro recurrent caries. J Dent 2001;29:255-273.

38. Owens BM, Lim DY, Arheart KL. The effect of antimicrobial pre-treatments on the performance of resin composite restorations. Oper Dent 2003;28:716-722.

39. Yiu CK, King NM, Suh BI, Sharp LJ, Carvalho RM, Pashley $\mathrm{DH}$, Tay FR. Incompatibility of oxalate desensitizers with acidic, fluoride-containing total-etch adhesives. J Dent Res 2005;84:730-735.

40. Tay FR, Pashley DH, Mak YF, Carvalho RM, Lai SC, Suh BI. Integrating oxalate desensitizers with total-etch two-step adhesive. J Dent Res 2003;82:703-707. 